\title{
Partially graphitized Iron-carbon hybrid composite as electrochemical supercapacitor material
}

\author{
Sai Rashmi Manippady, ${ }^{[a]}$ Ashish Singh, ${ }^{[b]}$ Chandra Sekhar Rout, ${ }^{[a]}$ Akshaya Kumar Samal, ${ }^{[a]}$ and \\ Manav Saxena ${ }^{*[a]}$
}

[a] Ms. S. R. Manippady, Dr. C. S. Rout, Dr. A. K. Samal, Dr. M. Saxena

Centre for Nano and Material Sciences

Jain University

Ramanagra, Bangalore-562112, Karnataka, India

E-mail: manavsaxena19@gmail.com, s.manav@jainuniversity.ac.in (MS)

[b] Dr. A. Singh

Department of Chemistry

Indian Institute of Technology Kanpur

Kanpur, Uttar Pradesh-208016, India

\begin{abstract}
The conversion of biomass into valuable carbon composites as an efficient non-precious energy storage electrode material has elicited extensive research interests. As synthesized partially graphitized iron oxide-carbon composite material $\left(\mathrm{Fe}_{3} \mathrm{O}_{4} / \mathrm{Fe}_{3} \mathrm{C} @ \mathrm{C}\right)$ shows an excellent property as an electrode material for supercapacitor. X-ray diffraction analysis, high resolution transmission electron microscopy, $X$-ray photo-electron spectroscopy and Brunauer-Emmett-Teller analysis is used to study the structural, compositional and surface areal properties. The electrode material shows a specific surface area of $827.4 \mathrm{~m}^{2} / \mathrm{g}$. Due to the synergistic effect of graphitic layers with iron oxide/carbide, $\mathrm{Fe}_{3} \mathrm{O}_{4} / \mathrm{Fe}_{3} \mathrm{C} @ \mathrm{C}$ hybrid electrode materials display high-performance for supercapacitor with excellent capacity of $878 \mathrm{~F} / \mathrm{g}$ at a current density of $5 \mathrm{~A} / \mathrm{g}$ (3-electrode) and $211.6 \mathrm{~F} / \mathrm{g}$ at a current density of $0.4 \mathrm{~A} / \mathrm{g}$ (2electrode) in $6 \mathrm{M} \mathrm{KOH}$ electrolyte with good cyclic stability.
\end{abstract}

\section{Introduction}

The large percentage of energy consumed globally is generated from non-renewable fossil fuels. Although alleviating carbon emission is a multifaceted challenge, the cardinal of the future low-carbon economy will substantially dependent on renewable energy sources and storage systems. The ever-growing energy demand has stimulated intense research on economic, alternative energy storage systems with high efficiency and environmental benignity. ${ }^{[1]}$ Electrical energy from the renewable energy sources must be efficiently stored for on-demand utilization. ${ }^{[2]}$ In this scenario, electrochemistry provides a link for efficient intertransfer of chemical to electrical energy. ${ }^{[1 \mathrm{a}]}$ Electrochemically active mesoporous materials are particularly advantageous for applications in energy storage owing to their high surface areas and large pore volumes.

In the field of mesoporous materials, carbon-based functional materials represent the most investigated electrode materials for energy storage applications due to their excellent electrochemical activity as well as other advantages, including low costs and environmental friendliness. ${ }^{1}$ A gazillions of strategies have been attempted by choosing different precursors to design supercapacitor with pseudocapacitive electrodes of carbon and oxides of iron, ${ }^{[3]}$ manganese,${ }^{[4]}$ cobalt, ${ }^{[5]}$ vanadium,${ }^{[6]}$ ruthenium, ${ }^{[7]}$ tungsten, ${ }^{[8]}$ nickel, ${ }^{[9]}$ and mixed metals ${ }^{[10]}$ for the enhanced electrochemical properties. ${ }^{[3 a]}$ For carbon composites synthesis chemistry, activating agents (e.g $\mathrm{ZnCl}_{2}, \mathrm{KOH}, \mathrm{H}_{3} \mathrm{PO}_{4}$, $\mathrm{K}_{2} \mathrm{CO}_{3}$ ) are used to enhance the surface area, unique porosities and activity which add few extra steps in the synthesis procedure. Among different transition metal, being abundant, low cost and having high theoretical capacitance,${ }^{[11]}$ oxides of iron have gained widespread attentions and explored as an electrode material due to multiple valence states, rich redox pairs. The positive synergic coupling effects between the $\mathrm{Fe}_{\mathrm{x}} \mathrm{O}_{\mathrm{y}} \mathrm{H}_{z}$ and carbon are superintended for its superior properties related to the energy storage applications. ${ }^{[12]}$ Polypyrrole/ $/ \mathrm{Fe}_{2} \mathrm{O}_{3}$ composite material by $\mathrm{Xu}$ et al. display gravimetric capacitance of $560 \mathrm{Fg}^{-1}$ at current density of $5 \mathrm{Ag}^{-1}$ measured by three-electrode system while using $0.5 \mathrm{M} \mathrm{Na}_{2} \mathrm{SO}_{4}$ aqueous solution as electrolyte. ${ }^{[3 a]} \mathrm{Fe}_{2} \mathrm{O}_{3}$ nanoparticles decorated on graphene-carbon nanotubes display gravimetric capacitance of $675 \mathrm{Fg}^{-1}$ at $1 \mathrm{Ag}^{-1}$ measured by threeelectrode system in $6 \mathrm{M} \mathrm{KOH}$ electrolyte. ${ }^{[3 \mathrm{~b}]}$ Rudra et al. reported $\mathrm{Au}-\mathrm{Fe}_{2} \mathrm{O}_{3}$ composite nanorods having gravimetric capacitance of $\sim 570 \mathrm{Fg}^{-1}$ at $1 \mathrm{~A} \mathrm{~g} \mathrm{~g}^{-1}$ in $0.5 \mathrm{M}$ aq. $\mathrm{H}_{2} \mathrm{SO}_{4}$ in a three-electrode system. ${ }^{[3 c]}$ Ishaq et al. reported $232 \mathrm{Fg}^{-1}$ gravimetric capacitance of ternary composite $\mathrm{rGO} / \mathrm{MnFe}_{2} \mathrm{O}_{4} /$ polypyrrole electrode measured by two-electrode system in $1 \mathrm{M} \mathrm{H}_{2} \mathrm{SO}_{4}{ }^{[13]} \mathrm{Zhou}$. et al. reported gravimetric capacitance of $1116.6 \mathrm{Fg}^{-1}$ at $10 \mathrm{Ag}^{-1}$ current density in $1 \mathrm{M}$ aq. $\mathrm{Na}_{2} \mathrm{SO}_{4}$ for spindle-like carbon incorporated$\mathrm{Fe}_{2} \mathrm{O}_{3}$ grown on carbon nanotube fiber in a three-electrode system. ${ }^{[10 a]}$

Recently, the carbon derived from biomass especially biowaste, has sparked tremendous interest in the energy related material research. The potential candidacy of the biowaste derived carbon is primarily due to the inexpensiveness, sustainability, abundance, and environmental friendliness of the raw materials, as well as the high performance of the resultant carbon.

In the present study, we demonstrate a simple and effective strategy to synthesize the iron-carbon-based functional material, the composite of sustainable bagasse (Saccharum officinarum) and iron oxide/carbide. Notably, bagasse is a waste biomass (dry fibrous residue) that remains after sugarcane stalks are crushed to extract their juice with a composition of $32-34 \%$ cellulose, 19 $24 \%$ hemicellulose, $25-32 \%$ lignin, $6-12 \%$ extractives and $2-6 \%$ ash. ${ }^{[14]}$ The cane juice comprises mainly of sugar (sucrose) $9-12 \%$ $(w / v) .{ }^{[15]}$ Herein, we apply the high compatibility and coordinating capability of oxygen-containing groups (methoxy, carboxyl and phenolic) in bagasse with $\mathrm{Fe}^{3+}$ ions ${ }^{[16]}$ and realize the uniform 
distribution of iron oxide particles in the carbon matrix during the carbonization process. Benefiting from the synergistic effect of structure and component, the iron oxide doped partially graphitized carbon composite displays high-performance as $\mathrm{Fe}_{3} \mathrm{O}_{4} / \mathrm{Fe}_{3} \mathrm{C} @ \mathrm{C}$ hybrid electrode materials for supercapacitor with excellent capacity and rate capabilities in alkaline media.

\section{Results and Discussion}

Coordination of $\mathrm{Fe}^{3+}$ ions with oxygen functional groups present in the bagasse (methoxy, carboxyl, phenolic) from sugar, lignin moieties allows homogenous distribution of $\mathrm{Fe}^{3+}$ ions ${ }^{[16]}$ and thus during carbonization, iron oxide particles uniformly embedded in the carbon matrix. The synthesis scheme and probable mechanism of graphitization is shown in Figure 1.

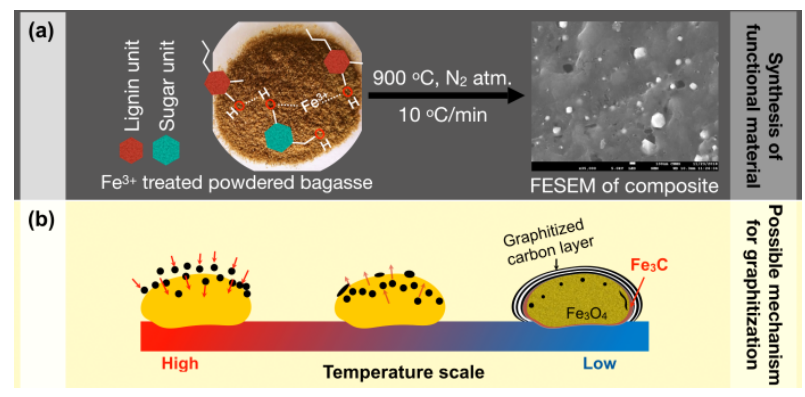

Figure 1: Schematic representation for (a) Synthesis of functional composite material, (b) Possible mechanism for graphitization and $\mathrm{Fe}_{3} \mathrm{C}$ formation.

The crystallographic structure of the CFO and CF10 were analyzed using PXRD pattern. The PXRD pattern of CF0 shows the broad peak at $2 \theta=23.3^{\circ}$ and $43.8^{\circ}$ refers to the $(002)$ and (100) plane of carbon, and indicates the amorphous nature of the carbon (Figure S1). ${ }^{[17]}$ PXRD of CF10 shows sharp peaks suggesting the crystalline nature/crystallites in the material (Figure 2a). The distinct diffraction PXRD peaks of CF10 at $2 \theta=$ $(30.18,35.57,43.18,53.68,57.23,62.87,71.27,74.16$ and $79.15)^{\circ}$ corresponds to the (022), (131), (040), (242), (151), (044), (062), (353) and (444) crystal planes of the $\mathrm{Fe}_{3} \mathrm{O}_{4}$ (ref. code 96900-5839). The diffraction peaks at $2 \theta=(43.6,50.79 \text { and } 74.82)^{\circ}$ corresponds to the (111), (020) and (022) of Fe (ref. code 96-900$8470)$ respectively. Moreover, the peak at $2 \theta: 44.68^{\circ}$ correspond to the (031) crystal plane of the $\mathrm{Fe}_{3} \mathrm{C}$ (ref. code 96-901-6232). The characteristic peaks for carbon, $\mathrm{Fe}, \mathrm{Fe}_{3} \mathrm{O}_{4}$ and $\mathrm{Fe}_{3} \mathrm{C}$ suggesting the coexistence of $\mathrm{Fe}, \mathrm{Fe}_{3} \mathrm{O}_{4}, \mathrm{Fe}_{3} \mathrm{C}$ and carbon in the hybrid networks $\mathrm{Fe}_{3} \mathrm{O}_{4} / \mathrm{Fe}_{3} \mathrm{C} @ \mathrm{C}$ which is also supported by HRTEM.

The chemical compositions and valence states of the CF0 and CF10 composites were analyzed by $\mathrm{X}$-ray photoelectron spectroscopy (XPS) (Figure 2b, S2). The high-resolution Fe2p spectrum of CF-0 confirms the absence of iron species in CF0 (Figure S2). Figure $2 b$ shows the high-resolution Fe2p spectrum of CF10. The broad peak centered at $708.3 \mathrm{eV}$ is assigned as a merged peak for $\mathrm{Fe}(\mathrm{II}) 2 \mathrm{p}_{3 / 2}$ and $\mathrm{Fe}_{3} \mathrm{C}(\mathrm{Fe}-\mathrm{C}) .{ }^{[18] ~[19] ~[20] ~ T h e ~ p e a k ~}$ at $711.8 \mathrm{eV}$ is corresponding to $\mathrm{Fe}(\mathrm{III}) 2 \mathrm{p}_{3 / 2}$. Based on the above discussion, the presence of $\mathrm{Fe}_{3} \mathrm{O}_{4}$ and $\mathrm{Fe}_{3} \mathrm{C}$ could be concluded in the CF10. The Fe-concentration quantified in the CFO and CF10 is 0 and 1.4 at.\% respectively (Table S1).
Comparative Raman spectra of CF0 and CF10 are shown in Figure 2c. The G band for CF0 and CF10 are positioned at 1607 and $1589 \mathrm{~cm}^{-1}$ respectively. The FWHM of G-band of CFO and CF10 is $\sim 100.6 \mathrm{~cm}^{-1}$ which is much higher than the crystalline graphite. The D band of CFO and CF10 is positioned at $1349 \mathrm{~cm}^{-}$ 1. The FWHM of D-band of CF10 is $125.7 \mathrm{~cm}^{-1}$ as compared to $176.1 \mathrm{~cm}^{-1}$ of CF0. The decrease in the FWHM of D-band is due to the formation of ordered structure and thus suggests the presence of partial graphitized structure. A new peak at $2680 \mathrm{~cm}^{-}$ ${ }_{1}$ corresponding to $2 \mathrm{D}$ band that arises in CF10 confirms the presence of graphitized carbon structure which is absent in CF0. The graphitization of CF10 is also consistent with HRTEM and PXRD analysis.

The adsorption-desorption curves of CF0, CF10 and CF20 (Figure 2d and S3) were ascribed to typical type I (CF0) and type IV (CF10, CF20) profiles. The specific surface area (SSA) of CF10 is $\sim 828 \mathrm{~m}^{2} \mathrm{~g}^{-1}$ which is $\sim 12 \%$ higher than the CF0 $\left(\sim 740 \mathrm{~m}^{2} \mathrm{~g}^{-1}\right)$. The detailed textural properties are tabulated in Table S1. The pore size distribution (PSD) of CF10 reveals that the ratio of mesopores to micropores is $0.26,1.24$, and 2.3 for CF0, CF10 and CF20 respectively (Table $\mathrm{S} 2$ ). The ratio suggest that with increase in iron content the mesopores formation is preferred. The pore size distribution (PSD) for CF10 showed the pore diameters are in the range (1.2-1.5 nm) and (2.9-5.2 $\mathrm{nm}$ ) respectively. [21] The SSA of CF20 is $\sim 190 \mathrm{~m}^{2} \mathrm{~g}^{-1}$ which is lesser than CF0 and CF10 (Figure S3b). The decrease in CF20 SSA might be due to higher loading of iron oxide which occupied the void and surface space in the layered material. ${ }^{[22]}$
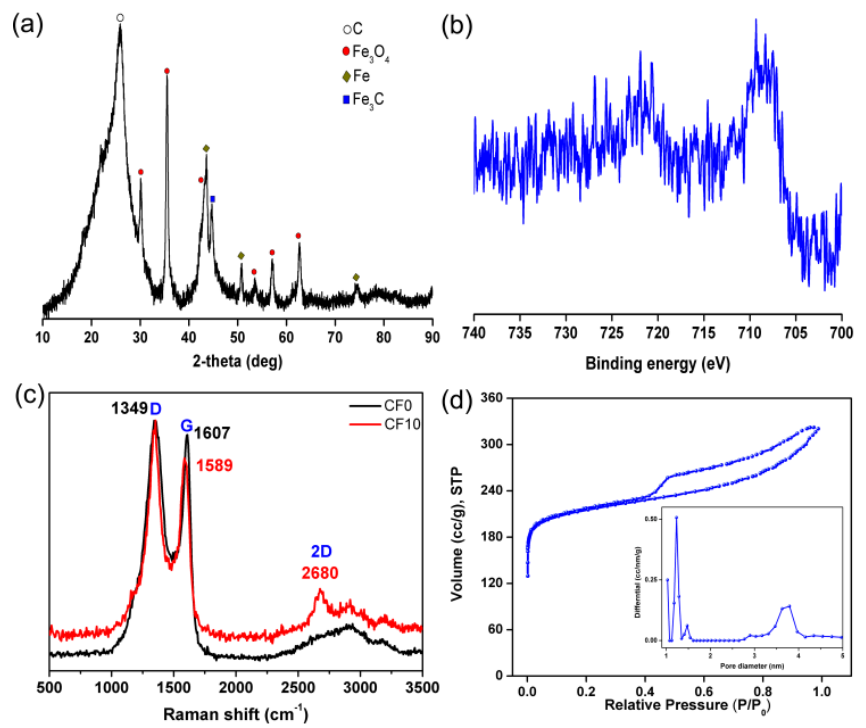

Figure 2: (a) PXRD, (b) Fe2p XPS spectrum, (c) Raman spectra of CF0, CF10, (d) $\mathrm{N}_{2}$ adsorption-desorption isotherms, inset: pore size distribution of CF10. 


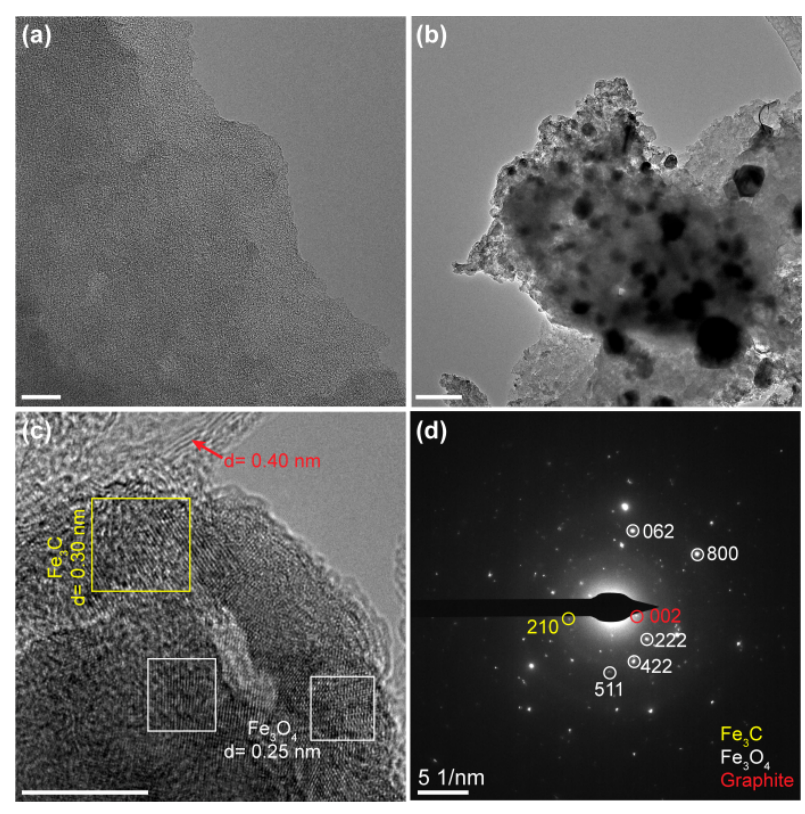

Figure 3: HRTEM images of (a) CF0, (b-c) CF10, (d) SAED of CF10. Scale bar: (a) $20 \mathrm{~nm}$, (b) $200 \mathrm{~nm}$, (c) $10 \mathrm{~nm}$, (d) $51 / \mathrm{nm}$.

Surface morphology of the control (CF0), CF10 and CF20 are analyzed through HRTEM. HRTEM reveals that CF-0 contains porous layered carbon structure (Figure 3a). The absence of graphitized layers indicates that CF0 is amorphous in nature which also supported by PXRD data (Figure S1). CF10 composite shows partial graphitized structures located around the polydisperse masses of $\mathrm{Fe}_{3} \mathrm{O}_{4} / \mathrm{Fe}_{3} \mathrm{C}$ distributed throughout the layered carbon structure (Figure $3 \mathrm{~b}$ ). The d-spacing of $2.5 \AA$ (white squares, Figure $3 \mathrm{c}, \mathrm{S} 4 \mathrm{a}$ ) matches to the (131) crystal plane of $\mathrm{Fe}_{3} \mathrm{O}_{4}$ (ref. code: 96-900-5839) which is also supported by $\operatorname{PXRD}\left(2 \theta=35.57^{\circ}\right)$. The $d$-spacing of $3.0 \AA$ (yellow square, Figure $3 c, S 4 b$ ), corresponds to the (111) crystal plane of $\mathrm{Fe}_{3} \mathrm{C}$ (ref. code: 96-901-6232). The formation of $\mathrm{Fe}_{3} \mathrm{C}$ is interesting and might be due to the high solubility of carbon in to the iron. The solubility of carbon in $\mathrm{Fe}$ is temperature-dependent and show higher solubility $\sim 7.0$ at. $\%$ at $1000^{\circ} \mathrm{C}$. At higher temperatures, the $\mathrm{Fe}^{3+}$ ions convert to $\mathrm{Fe}_{3} \mathrm{O}_{4}$ or $\mathrm{Fe}$ by carbon reduction and simultaneously carbon diffuses into the iron oxide particles. The temperature dependency leads to the carbon segregation from the bulk during cooling and catalyzed the growth of graphitized structure and iron carbide (Figure 1b). [23] The graphitized structures along the particles are defected having interlayer spacing of $4 \AA$ (marked with red arrow, Figure $3 \mathrm{c}$ ). The iron content in CFO and CF10 is further quantified using energy dispersive X-ray spectroscopy (EDS) during TEM analysis. The atomic percentage of Fe quantified in CF0 and CF10 are 0 and $1.6 \%$ respectively (Table $\mathrm{S} 1$ ) which is closer to 1.4 at.\% obtained from XPS. The amount of oxygen increases from 2 (CF0) to 5 (CF10) at.\% in presence of iron. The oxygen groups from lignin, sugar covalently bonded with iron and thus upon carbonization more oxygen retains with CF10 which is in well agreement with EDS and XPS analysis (Table S1).

The grown graphitized structures are defected and show 4.0 $\AA$ interlayer spacing corresponds to (002) plane which is also in

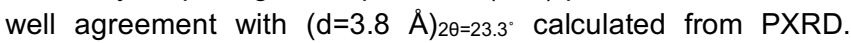
Selected area electron diffraction (SAED) pattern of CF10 shows characteristic diffraction spots for different planes of $\mathrm{Fe}_{3} \mathrm{O}_{4}, \mathrm{Fe}_{3} \mathrm{C}$ and graphitized carbon and thus confirms the formation of $\mathrm{Fe}_{3} \mathrm{O}_{4} / \mathrm{Fe}_{3} \mathrm{C} @ \mathrm{C}$ composite (Figure 3d). The CF20 composite also shows the layered structure impregnated with iron oxide nanoparticles similar to CF10 (Figure S5).

\section{Electrochemical performance of Carbon-iron composite:}

3-electrode system: The electrochemical performance of the CF0, CF10, CF20 and bare $\mathrm{Ni}$ foam is measured by cyclic voltammetry (CV) at a scan rate of $100 \mathrm{mV} / \mathrm{s}$ (Figure 4a). The materials show a pseudocapacitive behavior via redox couple of $\mathrm{Fe}^{2+} / \mathrm{Fe}^{3+}$. with an oxidation and reduction peaks. The CV curves of the bare $\mathrm{Ni}$ foam, CF0, CF20 at the $100 \mathrm{mV} / \mathrm{s}$ scan rate show the lesser area as compared to the CF10. A smaller area suggests the smaller value of $\mathrm{C}_{\mathrm{sp}}$ for bare $\mathrm{Ni}$ foam, CF0 and CF20 as compared to CF10 as $\mathrm{C}_{\mathrm{sp}}$ is directly related to the area under the CV curve. On the basis of above discussion, it could be concluded that CF10 has the best capacitive performance. The electrochemical performance of CF10 was studied by CV curves at different scan rates of 5, 10, 40, 80 and $100 \mathrm{mV} / \mathrm{s}$ (Figure 4b). The specific capacitance is measured using equation 1 . CF10 shows 443.3, 412.2, 259.7, 180.6 and $158.1 \mathrm{~F} / \mathrm{g}$ specific capacitance at $5,10,40,80$ and $100 \mathrm{mV} / \mathrm{s}$ scan rate respectively which is three times higher than CF0 $(141.3 \mathrm{~F} / \mathrm{g})$, and CF20 (230.8 F/g) at $5 \mathrm{mV} / \mathrm{s}$ (Figure S6, Table S3). This outstanding electrochemical performance and large area for CF10 composite may be due to the synergistic interaction between the $\mathrm{Fe}_{3} \mathrm{O}_{4} / \mathrm{Fe}_{3} \mathrm{C}$ nanoparticles with the carbon material. ${ }^{[2]}$ The highest specific capacitance is found to be for CF10 composite which has the optimal loading of $\mathrm{Fe}_{3} \mathrm{O}_{4} / \mathrm{Fe}_{3} \mathrm{C}$ nanoparticles. Further increase in metal oxide loading (CF20) leads to decrease in the specific capacitance. Though it is proved that the decrease in surface area results in decreases in specific capacitance, another reason might be excess loading of the iron oxide which will lead to an overall decrease of active surface area for electrochemical reactions in the CF20, and results the decreases the specific capacitance. ${ }^{[25]}$ Further, GCD cycles are shown in Figure $4 \mathrm{c}$ and the specific capacitance is measured from the discharge curve using equation 2. The quasi-triangular shape of the charge-discharge curve indicates pseudocapacitive nature of the composite due to faradaic transformation. ${ }^{[26]}$ The specific capacitance for CF10 calculated from GCD is $878.0,868.3,863.1,836.8$ and $800 \mathrm{~F} / \mathrm{g}$ at current densities of $5,6,7,8$ and $9 \mathrm{~A} / \mathrm{g}$ respectively which is higher than CF0 and CF20 with $\mathrm{C}_{\mathrm{sp}}$ of $25.7 \mathrm{~F} / \mathrm{g}$ and $381.6 \mathrm{~F} / \mathrm{g}$ at $5 \mathrm{~A} / \mathrm{g}$ (Table S3) respectively. The $\mathrm{C}_{\mathrm{sp}}$ of CF10 is higher than the reported results for $\mathrm{Fe}_{3} \mathrm{O}_{4} @$ hollow graphite shells $(481 \mathrm{~F} / \mathrm{g}, 1 \mathrm{~A} / \mathrm{g})$, ${ }^{[27]} \alpha-\mathrm{Fe}_{2} \mathrm{O}_{3} / \mathrm{rGO}$ flexible electrode $(714 \mathrm{~F} / \mathrm{g}, 1 \mathrm{~A} / \mathrm{g}),{ }^{[28]} \mathrm{Fe}_{3} \mathrm{O}_{4} / \mathrm{rGO}$ nanosheets hybrid $(455 \mathrm{~F} / \mathrm{g}, 3.6 \mathrm{~A} / \mathrm{g})$, [29] and $\mathrm{rGO} / \mathrm{Fe}_{2} \mathrm{O}_{3}$ composite $(577.5 \mathrm{~F} / \mathrm{g}, 2 \mathrm{~A} / \mathrm{g})^{[30]}$. Figure $4 \mathrm{~d}$ and $4 \mathrm{e}$ represent the specific capacitance as a function of scan rate and current density respectively. As the scan rate and current density increases, the specific capacitance displays a gradual attenuation from 443.3 $\mathrm{F} / \mathrm{g}$ (at $5 \mathrm{mV} / \mathrm{s}$ ) to $158.1 \mathrm{~F} / \mathrm{g}$ (at $100 \mathrm{mV} / \mathrm{s}$ ) with capacitance retention of $\sim 36 \%$. The increase in current density results in a decrease in $\mathrm{C}_{\mathrm{sp}}$ due to the slow redox reaction rate at high current density. ${ }^{[31]}$ The decrease in specific capacitance is due to the diffusion limitation and underutilization of the active material at higher specific currents. ${ }^{[32]}$ The contribution of Ni foam substrate to the capacitances is found negligible. Importantly, for the application point of view, cyclic stability of an electrode material 
plays a significant role. For CF10 composite, after 5000 chargedischarge cycles, $\mathrm{C}_{\mathrm{sp}}$ is found to be $101.0 \mathrm{~F} / \mathrm{g}$ (Figure $4 \mathrm{f}$ ), which is $\sim 84 \%$ of its initial capacitance after stabilization at $50 \mathrm{~A} / \mathrm{g}$ current density. Also, the electrode material shows higher cyclic stability as compared to earlier reports. ${ }^{[33]}$ Hence, having good stability enables the material for its practical applicability.

Furthermore, the EIS is carried out to understand the capacitive and resistive behavior of CF10 and CF0 within the frequency range of $0.5 \mathrm{~Hz}$ to $100 \mathrm{kHz}$ with $1 \mathrm{mV}$ amplitude with an open circuit perturbation potential of $5 \mathrm{mV}$. In the Nyquist plot, high frequency is semicircle region indicating the charge transfer resistance $\left(R_{c t}\right)$ and low-frequency area is the straight line indicating the diffusion of ions in electrode material. ${ }^{[29]}$ Nyquist plot with Randle's equivalent circuit (inset) depicted in Figure $4 \mathrm{~g}$ shows that for CF10, the $R_{c t}$ value is $1.77 \Omega$ with less inclined line as compared to the CF0 with $R_{c t}$ value of $2.85 \Omega$. The $R_{s}$ value is found to be $0.92 \Omega$ and $1.38 \Omega$ for CF10 and CF0 respectively. The increase in $R_{c t}$ value is due to the low charge transfer rate seen in control sample. Hence the high capacitance of CF10 results from the low equivalent series resistance.
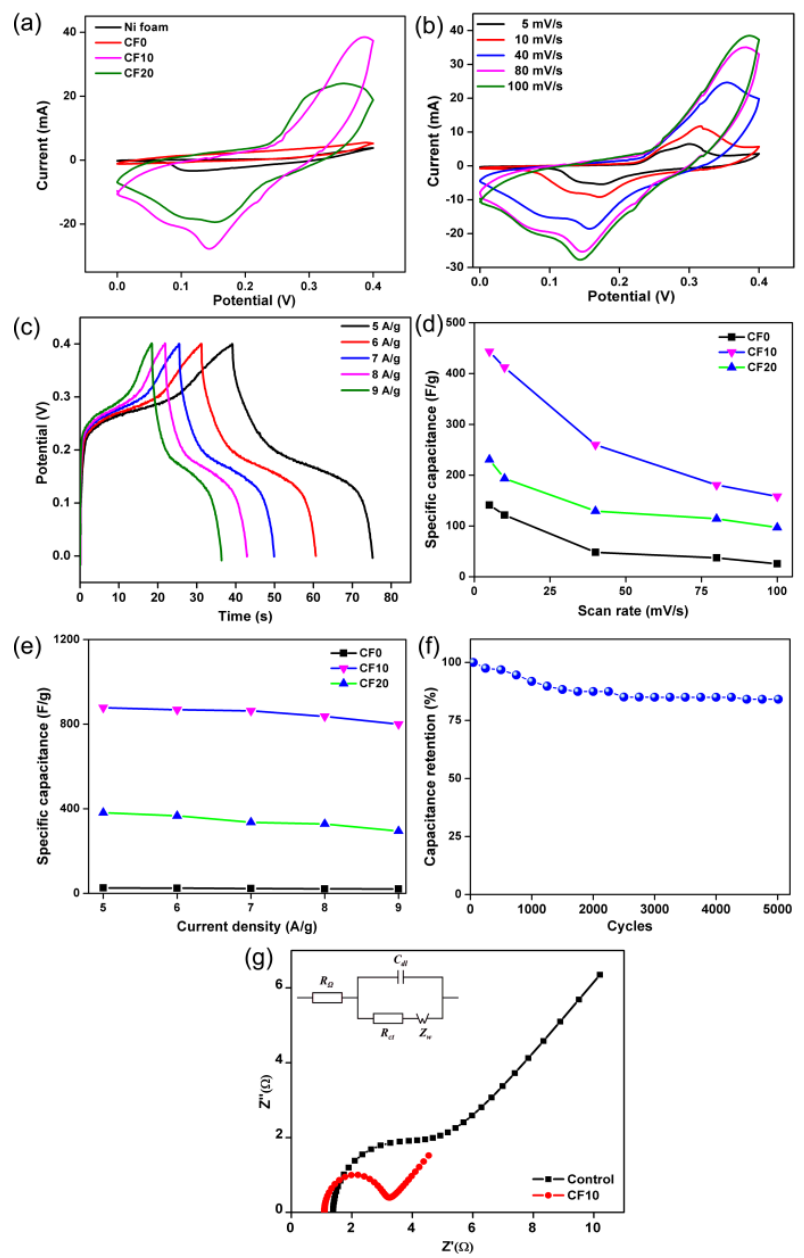

Figure 4: Electrochemical characterization. (a) CV curves at $100 \mathrm{mV} / \mathrm{s}$ for bare $\mathrm{Ni}$ foam, CF0, CF10 and CF20, (b) CV curves of CF10 at different scan rates, (c) Galvanostatic charge-discharge curves at different current densities for CF10, (d) Deviation in specific capacitance at different scan rate, (e) Deviation in specific capacitance at different current densities, (f) Cycling performance of the CF10 at $50 \mathrm{~A} / \mathrm{g}$ current density, (g) EIS Nyquist plot for CF0 and CF10, inset showing equivalent circuit.

\section{2-electrode system:}

The CV curve obtained for the symmetric capacitor is measured using a potential window of 0-1 $\mathrm{V}$ at different sweep rates. The cyclic voltammetry of CF10 shows a more rectangular shape graph representing an ideal capacitive behavior, resulting in the low charge transfer resistance which further leads to better ion diffusion ${ }^{[34]}$ (Figure $5 a$ ). Figure $5 a$ and $5 b$ show the CV of CF10 at different scan rates and GCD plot at different discharge current densities respectively. The calculated specific capacitance values of CF10 from CV are 163.9, 161.5, 143.2 and $135.4 \mathrm{~F} / \mathrm{g}$ at 40, 80, 100 and $200 \mathrm{mV} / \mathrm{s}$ scan rate respectively. The higher capacitance with a slower scan rate is due to the well interaction of electrolyte and the electrode material. Further, GCD curves depict almost triangular shape suggesting good columbic efficiency and electrochemical reversibility. The specific capacitances calculated from GCD curves are 211.6, 203.9, 197.5 and $193.8 \mathrm{~F} / \mathrm{g}$ at 0.4 , $0.7,1$ and $2.5 \mathrm{~A} / \mathrm{g}$ respectively. The specific capacitance 163.9 $\mathrm{F} / \mathrm{g}(40 \mathrm{mV} / \mathrm{s})$ and $211.6 \mathrm{~F} / \mathrm{g}(0.4 \mathrm{~A} / \mathrm{g})$ of CF10 is higher than the recently reported value e.g. $169.5 \mathrm{~F} / \mathrm{g}(0.5 \mathrm{~A} / \mathrm{g})$ using $\mathrm{Fe}_{2} \mathrm{O}_{3} / \mathrm{GNs} / \mathrm{CNTs}$ conductive networks, ${ }^{[3 \mathrm{~b}]} 162.9 \mathrm{~F} / \mathrm{g}(5 \mathrm{mV} / \mathrm{s})$ of $\mathrm{rGO} / \mathrm{NiFe}_{2} \mathrm{O}_{4} / \mathrm{Ppy}^{[13]}, 182 \mathrm{~F} / \mathrm{g}(2 \mathrm{~A} / \mathrm{g})$ of $\mathrm{CuCo}_{2} \mathrm{O}_{4} / / \mathrm{G} @ \mathrm{Fe}_{3} \mathrm{O}_{4}{ }^{[3 \mathrm{e}]}$. The specific energy of CF10 material is found to be $29.4 \mathrm{Wh} / \mathrm{Kg}$, power density of $807 \mathrm{~W} / \mathrm{Kg}$. We have measured GCD cycles to understand the cyclic stability of the CF10 within the potential window of $1.0 \mathrm{~V}$ at a current density of $20 \mathrm{~A} \mathrm{~g}^{-1}$ for 5000 cycles. Figure $5 \mathrm{c}$ shows the retention of specific capacitance for CF10 as a function of the cycle number. Interestingly, we observed that the CF10 show retention of $\sim 94 \%$ of its specific capacitance after stabilization, which is higher than the earlier reports. ${ }^{[33 a, 35]}$ The GCD curves of CF10 at $20 \mathrm{~A} / \mathrm{g}$ discharge current densities after $1^{\text {st }}, 100^{\text {th }}, 500^{\text {th }}, 1000^{\text {th }}, 2000^{\text {th }}, 3000^{\text {th }}, 4000^{\text {th }}$ and $5000^{\text {th }}$ cycle confirm that CF10 has good stability (Figure $5 \mathrm{~d}$ ).
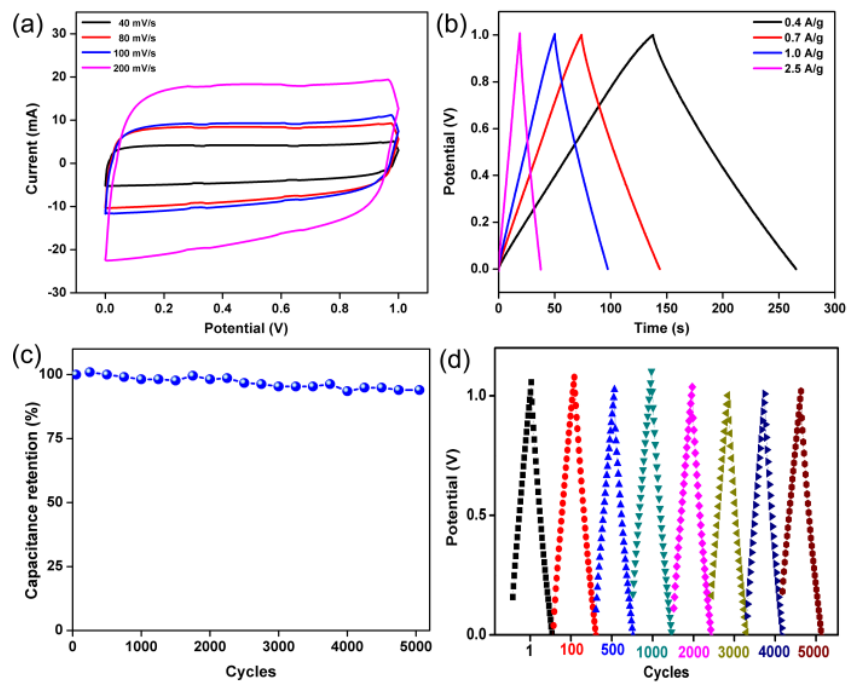

Figure 5: Electrochemical characterization of CF-10 (a) CV curves at different scan rate, (b) GCD curves at different current densities, (c) Cyclic stability measurements of CF10 at $20 \mathrm{~A} / \mathrm{g}$ current density, (d) Comparison of the GCD curves at $20 \mathrm{~A} / \mathrm{g}$ after selected cycles. 
Table 1. Comparison in specific capacitance of three and two electrode system with different material.

\begin{tabular}{|c|c|c|c|}
\hline \multirow{2}{*}{ Electrode material } & \multicolumn{2}{|c|}{ Specific capacitance ${ }^{[\mathrm{b}]}$} & \multirow{2}{*}{ Ref } \\
\hline & 3-electrode & 2-electrode & \\
\hline $\begin{array}{l}\text { Neem leaves } \\
\text { derived carbon }\end{array}$ & $400 \mathrm{~F} / \mathrm{g}(0.5 \mathrm{~A} / \mathrm{g})$ & - & [17] \\
\hline $\begin{array}{l}\mathrm{Fe}_{2} \mathrm{O}_{3} \text {-poly(t-butyl } \\
\text { acrylate)-block- } \\
\text { polyacrylonitrile }\end{array}$ & $235 \mathrm{~F} / \mathrm{g}(0.5 \mathrm{~A} / \mathrm{g})$ & - & [21] \\
\hline $\begin{array}{l}\text { Recycled Jute } \\
\text { derived carbon }\end{array}$ & $185 \mathrm{~F} / \mathrm{g}(0.5 \mathrm{~A} / \mathrm{g})$ & $51 \mathrm{~F} / \mathrm{g}(5 \mathrm{mV} / \mathrm{s})$ & [36] \\
\hline $\mathrm{rGO} / \mathrm{Fe}_{3} \mathrm{O}_{4} / \mathrm{PANI}$ & $631.7 \mathrm{~F} / \mathrm{g}(1.0 \mathrm{~A} / \mathrm{g})$ & $283.4 \mathrm{~F} / \mathrm{g}(1 \mathrm{~A} / \mathrm{g})$ & [26a] \\
\hline $\begin{array}{l}\mathrm{Fe}_{3} \mathrm{O}_{4} @ \text { Carbon } \\
\text { Nanosheets }\end{array}$ & $586.0 \mathrm{~F} / \mathrm{g}(0.5 \mathrm{~A} / \mathrm{g})$ & $58.5 \mathrm{~F} / \mathrm{g}(1 \mathrm{~A} / \mathrm{g})$ & [35] \\
\hline $\begin{array}{l}\text { Fe Composite algal } \\
\text { biochar }\end{array}$ & $418.0 \mathrm{~F} / \mathrm{g}(1 \mathrm{~A} / \mathrm{g})$ & 368 F/g (1 A/g) & [22b] \\
\hline $\begin{array}{l}\text { Polypyrrole- } \mathrm{Fe}_{2} \mathrm{O}_{3} \\
\text { nanohybrids }\end{array}$ & $560.0 \mathrm{~F} / \mathrm{g}(5 \mathrm{~A} / \mathrm{g})$ & - & [3a] \\
\hline $\begin{array}{l}\text { Porous N-doped } \\
\text { CNTs/Fe }{ }_{3} \mathrm{C}\end{array}$ & $181.0 \mathrm{~F} / \mathrm{g}(0.1 \mathrm{~A} / \mathrm{g})$ & - & [37] \\
\hline $\begin{array}{l}\mathrm{BiFeO}_{3} \text { nanowire- } \\
\mathrm{rGO} \text { nanocomposite }\end{array}$ & $928.4 \mathrm{~F} / \mathrm{g}(5 \mathrm{~A} / \mathrm{g})$ & $300 \mathrm{~F} / \mathrm{g}(5 \mathrm{~A} / \mathrm{g})$ & {$[10 c]$} \\
\hline $\begin{array}{l}\mathrm{Fe}_{3} \mathrm{O}_{4} \text { particles } \\
\text { coated with } \\
\text { nitrogen-doped } \\
\text { carbon }\end{array}$ & $313.0 \mathrm{~F} / \mathrm{g}(0.5 \mathrm{~A} / \mathrm{g})$ & - & [3d] \\
\hline $\begin{array}{l}\mathrm{CNT}-\mathrm{Fe}_{3} \mathrm{O}_{4}-\mathrm{PANI} \\
\text { film }\end{array}$ & - & $201 \mathrm{~F} / \mathrm{g}(20 \mathrm{mV} / \mathrm{s})$ & [38] \\
\hline $\begin{array}{l}\text { Sugar waste spent } \\
\text { derived carbon }\end{array}$ & $121.4 \mathrm{~F} / \mathrm{g}(0.1 \mathrm{~A} / \mathrm{g})$ & $105 \mathrm{~F} / \mathrm{g}(0.2 \mathrm{~A} / \mathrm{g})$ & [39] \\
\hline $\begin{array}{l}\text { Porous } \mathrm{Fe}_{2} \mathrm{O}_{3} \\
\text { nanocluster }\end{array}$ & $357 \mathrm{~F} / \mathrm{g}(10 \mathrm{mV} / \mathrm{s})$ & - & [40] \\
\hline $\begin{array}{l}\mathrm{Fe}_{3} \mathrm{O}_{4} \text {-carbon } \\
\text { composite }\end{array}$ & $878.0 \mathrm{~F} / \mathrm{g}(5 \mathrm{~A} / \mathrm{g})$ & $\begin{array}{c}211.6 \mathrm{~F} / \mathrm{g}(0.4 \\
\mathrm{A} / \mathrm{g})\end{array}$ & $\begin{array}{l}\text { Present } \\
\text { work }\end{array}$ \\
\hline
\end{tabular}

[a] Capacitance value in 3 and 2-electrode configuration at mentioned discharge current

\section{Conclusion}

A simple strategy toward synthesis of the carbon-based functional material $\left(\mathrm{Fe}_{3} \mathrm{O}_{4} / \mathrm{Fe}_{3} \mathrm{C} @ \mathrm{C}\right.$ ) from bagasse and iron oxide is developed. By utilizing the high compatibility and coordinating capability of oxygen-containing groups of bagasse (from sugar and lignin moieties) with $\mathrm{Fe}^{3+}$, we have synthesized the composite having uniform distribution of iron oxide/carbide particles in the carbon matrix post carbonization. Due to the synergistic effect of graphitic layers with iron oxide/carbide, $\mathrm{Fe}_{3} \mathrm{O}_{4} / \mathrm{Fe}_{3} \mathrm{C} @ \mathrm{C}$ hybrid electrode materials (CF10) display high-performance for supercapacitor with excellent capacity of $878 \mathrm{~F} / \mathrm{g}$ at a current density of $5 \mathrm{~A} / \mathrm{g}$ (3-electrode) and $211.6 \mathrm{~F} / \mathrm{g}$ at a current density of $0.4 \mathrm{~A} / \mathrm{g}$ (2-electrode) in $6 \mathrm{M} \mathrm{KOH}$ electrolyte with good cyclic stability.

\section{Experimental Section}

\section{Synthesis of the composite material}

$5 \mathrm{~g}$ of powdered bagasse $(<50 \mu \mathrm{m})$ was soaked in $20 \mathrm{~mL} \mathrm{Fe}\left(\mathrm{NO}_{3}\right)_{3} .9 \mathrm{H}_{2} \mathrm{O}$ solution, and kept for $24 \mathrm{~h}$. Two samples prepared by choosing 10 and $20 \%$ (wt\%) of $\mathrm{Fe}$-precursor (w.r.t. bagasse weight) were dried in hot air oven at $60{ }^{\circ} \mathrm{C}$ for $12 \mathrm{~h}$. The wt\% of iron used will be 1.38 and $2.76 \%$ respectively. The iron treated bagasse was carbonization at $900{ }^{\circ} \mathrm{C}$ (heating rate of $10^{\circ} \mathrm{C} / \mathrm{min}$ ) in a quartz tube furnace under a continuous flow of $\mathrm{N}_{2}$ gas at $1 \mathrm{~atm}$ pressure. The furnace temperature was maintained at $900{ }^{\circ} \mathrm{C}$ for $1 \mathrm{~h}$ and then cooled down to RT under $\mathrm{N}_{2}$ flow. The control sample was also synthesized without Fe-precursor and referred to CFO. The iron-treated samples were referred to CF10 and CF20, where the number $(10,20)$ represents the weight percentage of iron precursor $\mathrm{Fe}\left(\mathrm{NO}_{3}\right)_{3} .9 \mathrm{H}_{2} \mathrm{O}$ used as mentioned above.

\section{Material Characterization}

Nitrogen sorption isotherms were recorded at $77 \mathrm{~K}$ using BrunauerEmmett-Teller (BET), surface area analyzer (Bellsorp Max, Japan). Based on the Barrett-Joyner-Halenda (BJH) model, pore size distribution plots were recorded from the desorption isotherms. Prior to the measurement the samples were degassed at $200^{\circ} \mathrm{C}$ under vacuum for $12 \mathrm{~h}$. Powder $\mathrm{X}$ ray diffraction (PXRD) (Rigaku X-ray diffraction ultima-IV, Japan) was recorded over a range of $5^{\circ}$ to $90^{\circ}$ with a scan speed of $1 \mathrm{deg} / \mathrm{min}$ using Cu-Ka radiation. The Surface morphology of the samples was studied using Thermo Scientific ${ }^{\mathrm{TM}}$ Talos ${ }^{\mathrm{TM}}$ F200S High-Resolution Transmission Electron Microscope (HRTEM). X-ray photoelectron spectroscopic (XPS) characterization was performed by PHI 5000 Versa Probll, FEI Inc. Raman spectra was recorded using Horiba Jobin Yvon Xplora Plus V1.2 Multiline with $532 \mathrm{~nm}$ excitation wavelength.

\section{Electrochemical Characterization:}

Cyclic voltammetry (CV), Galvanostatic charge-discharge (GCD) and electrochemical impedance spectroscopy (EIS) were done using CHI660D potentiostat ( $\mathrm{CH}$ instruments, Austin, USA).

3-electrode system: To carry out the electrochemical measurements, the synthesized hybrid materials were used as the working electrode, platinum wire as the counter electrode and $\mathrm{Ag} / \mathrm{AgCl}$ (sat. $\mathrm{KCl}$ ) as reference electrode. The working electrode material was prepared by mixing sample, super-p conducting carbon and polyvinylidene difluoride (PVDF) in a weight ratio of 80:10:10 in N-methyl-2-pyrrolidone (NMP) solvent. $1 \mathrm{mg}$ active material was coated on the cleaned Ni-foam substrate in $0.8 \mathrm{~cm}^{2}$ area and used as a working electrode. These electrodes were then dried in an oven for $12 \mathrm{~h}$ at $60^{\circ} \mathrm{C}$ and then kept in vacuum desiccators for $2 \mathrm{~h}$. The dried electrode substrates were compressed using a hydraulic press (pressure of $\sim 5$ tons). Further, the electrochemical studies were carried out using $6 \mathrm{M} \mathrm{KOH}$ solution as an electrolyte. The specific capacitance was calculated from $C V$ and $G C D$ were using by following equation (1) and (2) respectively. ${ }^{[8]}$

\section{2-electrode system:}

The prepared slurry $(2.5 \mathrm{mg})$ was coated on one side of two circular $\mathrm{Ni}$ foams of diameter $1 \mathrm{~cm}$. The modified nickel foams were dried in an oven at $60^{\circ} \mathrm{C}$ for $12 \mathrm{~h}$ and kept in vacuum desiccators for $2 \mathrm{~h}$. Whatman paper dipped in $6 \mathrm{M} \mathrm{KOH}$ was used as a separator during device fabrication using a Swagelok system made from stainless steel. The specific capacitance in two-electrode systems was calculated from $\mathrm{CV}$ and GCD using equation (3) and (4) respectively. ${ }^{[8]}$

$$
\begin{aligned}
& C_{s p}=2\left[m s\left(V_{a}-V_{b}\right)\right]^{-1} \int I(V) d V \\
& C_{s p}=I t /\left[m\left(V_{a}-V_{b}\right)\right] \\
& C_{s p}=\left[m s\left(V_{a}-V_{b}\right)\right]^{-1} \int 2[I(V) d V] \\
& C_{s p}=4 I t /\left[m\left(V_{a}-V_{b}\right)\right]
\end{aligned}
$$

where $\mathrm{C}_{\mathrm{sp}}(\mathrm{F} / \mathrm{g})$ denotes the specific capacitance, area under the $\mathrm{CV}$ curve is the integral part represented in the numerator, ' $m$ ' is the active mass of 
the material deposited on the Nickel foam substrate, ' $s$ ' is the scan rate and $\left(\mathrm{V}_{\mathrm{a}}-\mathrm{V}_{\mathrm{b}}\right)$ is the working potential window. Further the energy and power density of the device were calculated using the equation (5) and (6) respectively.

$E=\frac{1}{2} C \Delta V^{2}$

$P=\frac{E}{\Delta t}$

where $\mathrm{E}(\mathrm{Wh} / \mathrm{kg})$ is the specific energy, $\Delta \mathrm{V}$ is the potential window and $\mathrm{P}$ $(\mathrm{W} / \mathrm{Kg})$ is the specific power respectively.

\section{Acknowledgements}

SRM acknowledges Jain University for Junior Research fellowship. MS is grateful to the SERB, New Delhi, India for funding to conduct the research (EMR/2017/003368). The authors acknowledge Nanomission project (SR/NM/NS-20/2014) for FESEM \& PXRD facilities. The authors acknowledge the TEM Facility, funded by a TPF Nanomission, Gol project and Raman characterization at Centre for Nano and Soft Matter Sciences, Bengaluru and Indian Institute of Technology Kanpur, India for XPS characterization.

\section{Conflict of Interest}

Authors declare no conflict of interest.

\section{Author Contributions}

All authors have given approval to the final version of the manuscript.

Keywords: Bagasse • supercapacitor • composite material • iron carbide $\cdot$ iron oxide

[1] (a) Z.-L. Wang, D. Xu, H.-X. Zhong, J. Wang, F.-L. Meng, X.-B. Zhang, Sci. Adv. 2015, 1, e1400035; (b) W. Li, J. Liu, D. Zhao, Nat. Rev. Mat. 2016, 1, 16023.

[2] Y. Shao, M. F. El-Kady, J. Sun, Y. Li, Q. Zhang, M. Zhu, H. Wang, B. Dunn, R. B. Kaner, Chem. Rev. 2018, 118, 92339280.

[3] (a) C. Xu, A. R. Puente-Santiago, D. Rodríguez-Padrón, A. Caballero, A. M. Balu, A. A. Romero, M. J. Muñoz-Batista R. Luque, ACS Appl. Energy Mater. 2019, 2, 2161-2168; (b) Y. Tian, X. Hu, Y. Wang, C. Li, X. Wu, ACS Sustain. Chem. Eng. 2019, 7, 9211-9219; (c) S. Rudra, A. K. Nayak, S. Koley, R. Chakraborty, P. K. Maji, M. Pradhan, ACS Sustain. Chem. Eng. 2019, 7, 724-733; (d) J. Zhou, C. Zhang, T. Niu, R. Huang, S. Li, J. Z. Zhang, J. G. Chen, ACS Appl. Energy Mater. 2018, 1, 4599-4605; (e) J. Lin, H. Liang, H. Jia, S. Chen, J. Guo, J. Qi, C. Qu, J. Cao, W. Fei, J. Feng, J. Mater. Chem. A 2017, 5, 24594-24601.

[4] S. Bag, C. R. Raj, J. Mater. Chem. A 2016, 4, 8384-8394.

[5] S. Yang, Y. Liu, Y. Hao, X. Yang, W. A. Goddard III, X. L. Zhang, B. Cao, Adv. Sci. 2018, 5, 1700659.

[6] B. D. Boruah, S. Nandi, A. Misra, ACS Appl. Energy Mater. 2018, 1, 1567-1574.

[7] S. Mitra, K. S. Lokesh, S. Sampath, J. Power Sources 2008, 185, 1544-1549.

[8] R. Samal, B. Chakraborty, M. Saxena, D. J. Late, C. S. Rout, ACS Sustain. Chem. Eng. 2019, 7, 2350-2359.

[9] B. Senthilkumar, Z. Khan, S. Park, K. Kim, H. Ko, Y. Kim, J. Mater. Chem. A 2015, 3, 21553-21561.
[10] (a) Z. Zhou, Q. Zhang, J. Sun, B. He, J. Guo, Q. Li, C. Li, L Xie, Y. Yao, ACS Nano 2018, 12, 9333-9341; (b) A. Samanta, C. R. Raj, J. Electroanal. Chem. 2019, 847, 113183; (c) D. Moitra, C. Anand, B. K. Ghosh, M. Chandel, N. N. Ghosh, ACS Appl. Energy Mater. 2018, 1, 464-474 (d) S. Kumar, G. Saeed, N. H. Kim, J. H. Lee, J. Mater. Chem. A 2018, 6, 7182-7193; (e) R. Kumar, P. Rai, A. Sharma, J. Mater. Chem. A 2016, 4, 17512-17520.

[11] X. Chen, K. Chen, H. Wang, D. Xue, Materials Focus 2015 4, 78-80.

[12] B. Zhao, Y. Zheng, F. Ye, X. Deng, X. Xu, M. Liu, Z. Shao, ACS Appl. Mater. Interfaces 2015, 7, 14446-14455.

[13] S. Ishaq, M. Moussa, F. Kanwal, M. Ehsan, M. Saleem, T. N. Van, D. Losic, Sci. Rep. 2019, 9, 5974

[14] S. Haghdan, S. Renneckar, G. D. Smith, in Lignin in Polymer Composites (Eds.: O. Faruk, M. Sain), William Andrew Publishing, 2016, pp. 1-11.

[15] D. Mondal, S. K. Nataraj, A. V. Rami Reddy, K. K. Ghara, P. Maiti, S. C. Upadhyay, P. K. Ghosh, RSC Advances 2015, 5, 17872-17878.

[16] E. M. Soliman, S. A. Ahmed, A. A. Fadl, Arabian Journal of Chemistry 2011, 4, 63-70.

[17] M. Biswal, A. Banerjee, M. Deo, S. Ogale, Energy Environ. Sci. 2013, 6, 1249-1259.

[18] H. Huang, X. Feng, C. Du, S. Wu, W. Song, Journal of Materials Chemistry A 2015, 3, 4976-4982.

[19] N. S. Mclntyre, D. G. Zetaruk, Analytical Chemistry 1977, 49, 1521-1529.

[20] I. N. Shabanova, V. A. Trapeznikov, Journal of Electron Spectroscopy and Related Phenomena 1975, 6, 297-307.

[21] Y. Lin, X. Wang, G. Qian, J. J. Watkins, Chem. Mater. 2014 26, 2128-2137.

[22] (a) W. Chen, S. Li, C. Chen, L. Yan, Adv. Mater. 2011, 23 5679-5683; (b) S. E. M. Pourhosseini, O. Norouzi, P. Salimi, H. R. Naderi, ACS Sustain. Chem. Eng. 2018, 6, 4746-4758. (a) L. Chen, Z. Kong, S. Yue, J. Liu, J. Deng, Y. Xiao, R. G. Mendes, M. H. Rümmeli, L. Peng, L. Fu, Chem. Mater. 2015, 27, 8230-8236; (b) D. Kondo, K. Yagi, M. Sato, M Nihei, Y. Awano, S. Sato, N. Yokoyama, Chem. Phys. Lett. 2011, 514, 294-300; (c) S. lijima, T. Ichihashi, Nature 1993 363, 603-605; (d) S. Fan, M. G. Chapline, N. R. Franklin, T. W. Tombler, A. M. Cassell, H. Dai, Science 1999, 283, 512514; (e) Y. You, M. Yoshimura, S. Cholake, G.-H. Lee, V. Sahajwalla, R. Joshi, Adv. Mater. Interfaces 2018, 5, 1800599.

[24] (a) S. Sheng, W. Liu, K. Zhu, K. Cheng, K. Ye, G. Wang, D. Cao, J. Yan, J. Colloid Interface Sci. 2019, 536, 235-244; (b) X. Zhang, M. Zhu, T. Ouyang, Y. Chen, J. Yan, K. Zhu K. Ye, G. Wang, K. Cheng, D. Cao, Chem. Eng. J. 2019, $360,171-179$.

[25] K. A. Owusu, L. Qu, J. Li, Z. Wang, K. Zhao, C. Yang, K. M. Hercule, C. Lin, C. Shi, Q. Wei, L. Zhou, L. Mai, Nat. Commun. 2017, 8, 14264.

[26] (a) S. Mondal, U. Rana, S. Malik, J. Phys. Chem. C 2017 121, 7573-7583; (b) S. Zeng, H. Chen, F. Cai, Y. Kang, M. Chen, Q. Li, J. Mater. Chem. A 2015, 3, 23864-23870.

[27] H. Khani, D. O. Wipf, ACS Appl. Mater. Interfaces 2017, 9 6967-6978.

[28] H. Zhang, C. Lu, C. Chen, L. Xie, P. Zhou, Q. Kong, ChemElectroChem 2017, 4, 1990-1996.

[29] R. Kumar, R. K. Singh, A. R. Vaz, R. Savu, S. A. Moshkalev, ACS Appl. Mater. Interfaces 2017, 9, 8880-8890.

[30] M. Saraf, K. Natarajan, Shaikh M. Mobin, RSC Adv. 2017 7, 309-317.

[31] M. Zhi, C. Xiang, J. Li, M. Li, N. Wu, Nanoscale 2013, 5, 7288.

[32] R. Pai, A. Singh, S. Simotwo, V. Kalra, Adv. Eng. Mater. 2018, 20, 1701116

[33] (a) Z. Ma, X. Huang, S. Dou, J. Wu, S. Wang, J. Phys. Chem. C 2014, 118, 17231-17239; (b) A. Pathak, A. S Gangan, S. Ratha, B. Chakraborty, C. S. Rout, J. Phys. Chem. C 2017, 121, 18992-19001.

[34] Y. Dou, T. Liao, Z. Ma, D. Tian, Q. Liu, F. Xiao, Z. Sun, J. Ho Kim, S. Xue Dou, Nano Energy 2016, 30, 267-275. 
[35] H. Fan, R. Niu, J. Duan, W. Liu, W. Shen, ACS Appl. Mater. Interfaces 2016, 8, 19475-19483.

[36] C. Zequine, C. K. Ranaweera, Z. Wang, P. R. Dvornic, P.

K. Kahol, S. Singh, P. Tripathi, O. N. Srivastava, S. Singh,

B. K. Gupta, G. Gupta, R. K. Gupta, Sci. Rep. 2017, 7, 1174

[37] Y. Wang, G. Zhang, G. Liu, W. Liu, H. Chen, J. Yang, RSC Adv. 2016, 6, 44013-44018.

[38] J. Li, W. Lu, Y. Yan, T.-W. Chou, J. Mater. Chem. A 2017. $5,11271-11277$.

[39] A. Mahto, R. Gupta, K. K. Ghara, D. N. Srivastava, P. Maiti, K. D, P.-Z. Rivera, R. Meena, S. K. Nataraj, J. Hazard. Mater. 2017, 340, 189-201.

[40] J. W. Choi, I. W. Ock, K.-H. Kim, H. M. Jeong, J. K. Kang, Adv. Funct. Mater. 2018, 28, 1803695. 
